ORIGINAL PAPER

\title{
The significance of Angiogenesis For PRedicting OPTIMAL THERAPEUTIC RESPONSE IN CHRONIC MYELOID LEUKAEMIA PATIENTS
}

\author{
Irena Ćojbašić ${ }^{1,2}$, Lana Mačukanović-Golubović ${ }^{1,2}$, Dragan Mihailović ${ }^{2,3}$, Miodrag Vučićc ${ }^{1,2}$, \\ ŽARKO ĆOJBAŠIĆ ${ }^{4}$
}

\author{
${ }^{1}$ Clinic of Haematology and Clinical Immunology, Clinical Centre Niš, Serbia \\ ${ }^{2}$ Faculty of Medicine, University of Niš, Serbia \\ ${ }^{3}$ Institute of Pathology, Clinical Centre Niš, Serbia \\ ${ }^{4}$ Mechanical Engineering Faculty, University of Nišs, Serbia
}

\begin{abstract}
In this study the correlation and the prognostic value of the morphometric parameters of angiogenesis for optimal therapeutic response to tyrosine kinase inhibitor (TKI) therapy in patients with chronic myeloid leukaemia (CML), i.e. complete cytogenetic response $(\mathrm{CCgR})$ and major molecular response $(\mathrm{MMoR})$, were investigated. Microvascular density (MVD) and a number of different size- and shape-related morphometric parameters of microvessels of bone marrow biopsy from $40 \mathrm{CML}$ patients and 20 controls were examined. Microvessels of bone marrow were examined by using immunohistochemical staining for CD34 and quantified in the region of the most intense vascularisation by using image analysis.

CML patients had significantly higher angiogenesis parameters when compared with controls. A statistically significant correlation was found between some parameters of angiogenesis and evaluated $\mathrm{CCgR}$ and $\mathrm{MMoR}$. For achievement of $\mathrm{CCgR}$, lower values of MVD, minor axis, area, circularity, and roundness and higher value of aspect ratio, while for achievement of MMoR only lower values of MVD have been identified as positive prognostic factors.

Besides confirming increased angiogenesis in CML patients, this study also demonstrated prognostic significance of the degree of angiogenesis for the clinical outcome and identified angiogenic predictive factors for achieving optimal response on TKIs therapy.
\end{abstract}

Key words: chronic myeloid leukaemia, angiogenesis, microvessel morphometry, prognosis, outcome.

\section{Introduction}

Chronic myeloid leukaemia (CML) is a clonal myeloproliferative disease that is characterised by genetic abnormalities arising from a reciprocal translocation $\mathrm{t}(9 ; 22)(\mathrm{q} 34 ; \mathrm{q} 11)$ with subsequent formation of a fusion gene encoding constitutively active BCR$\mathrm{ABL}$ tyrosine kinase, which leads to the growth of leukaemia cells, an increase in the proliferation and cytokine-independent growth, inhibition of apoptosis, and linkage of alternative pathways $[1,2,3]$.

Angiogenesis plays a key role in the growth of the tumour, including its potential for invasion, metastasis, and progression [4, 5]. Obviously, angiogenesis and angiogenic factors play a significant role in the course and disease process of some leukaemias. It is assumed that in acute and chronic leukaemias $[6,7,8]$, as well in myelodysplastic syndrome $[9,10$, $11]$ and multiple myeloma [12], microvascular den- 
sity (MVD) has a significant impact on the spread of neoplastic cell clones. Among different leukaemias, the highest number of blood vessels and the largest vascular area are found in CML, which is associated with the highest plasma levels of vascular endothelial growth factor (VEGF), but not of basic fibroblast growth factor (bFGF) [13]. From myeloproliferative diseases, CML and myelofibrosis are related to higher MVD, elevated serum levels of angiogenic cytokines like VEGF, and increased number of VEGF-positive bone marrow cells in comparison to controls, suggesting that VGEF could be an important signal molecule for angiogenesis in these diseases [14, 15].

The gold standard in the treatment of patients with CML in chronic phase is the use of tyrosine kinase inhibitors (TKIs). Tyrosine kinase inhibitors induce high rates of $\mathrm{CCgR}$ and MMoR [16], and early achievement of CCgR [17] and MMoR [18] leads to better rates of overall survival and event-free survival. The effect of imatinib therapy on angiogenesis is a significant reduction of the microvessels and reticular fibres with marked decrease in megakaryocytes. The achievement of $\mathrm{CCgR}$ is correlated with a significant decrease of bone marrow vascularity, while the achievement of complete molecular response $(\mathrm{CMoR})$ is correlated with normalisation of MVD [19]. Furthermore, the value of MVD and the calibre of the small blood vessels are important predictors of patient survival and risk of progression [20]. It has been shown that imatinib reduces BCR-ABL-mediated VEGF secretion, which is largely responsible for the antiangiogenic effect of this drug [21].

The aim of this study was to investigate the correlation and prognostic significance of various morphometric parameters of angiogenesis in patients with chronic myeloid leukaemia, in relation to the achievement of complete cytogenetic and major molecular response to tyrosine kinase inhibitor therapy.

\section{Material and methods}

\section{Patients}

Bone marrow paraffin-embedded biopsies obtained at the time of diagnosis for 40 patients, with chronic phase CML diagnosed during 2009-2013 in our institution, were studied. Control bone marrow samples from 20 patients with no evidence of marrow disease, performed for diagnostic purposes as a part of staging procedure for Hodgkin's disease (6 cases) and non-Hodgkin's disease (14 cases), were also analysed. The study was approved by the Local Ethics Committee, and informed consent was obtained from each patient. The diagnosis of CML in chronic phase was determined according to the recommendations of the European LeukemiaNet panel [22, 23] as the presence in peripheral blood blasts of less than $15 \%$, blasts plus promyelocytes of less than $30 \%$, basophils of less than $20 \%$, platelet count of more than $100 \times 10^{9} / 1$, and no evidence of extra medullary disease. Patients with CML received TKIs - imatinib in an initial dose of $400 \mathrm{mg} /$ day orally. In patients with cytogenetic refractoriness or cytogenetic relapse an escalated dose of $800 \mathrm{mg} /$ day of imatinib or nilotinib was applied as well as dose reductions because of toxicities according to the recommendations of the European LeukemiaNet panel [22, 23].

\section{Evaluation before and during treatment}

The screening procedure included medical history, physical examination, blood counts, and differential and blood chemistry. All patients had pre-treatment blood marrow evaluation for morphology, histopathology, and cytogenetic analysis. After treatment was started, patients were evaluated with blood counts and differential and blood chemistry monthly. Bone marrow aspirate and cytogenetics were analysed every 6 months until CCgR was achieved and confirmed, and every year thereafter. The quantitative determination of BCR-ABL transcripts level were repeated every 3-4 months until MMoR response was achieved, and every six months thereafter.

\section{Response criteria}

The criteria for haematological and cytogenetic response were defined according to recommendations from the European LeukemiaNet panel [22, 23]. Complete haematological remission (CHR) was defined as normalisation of peripheral blood counts and differentials as white blood cell count of less than $10 \times 10^{9} / 1$, a platelet count of less than $450 \times 10^{9} / 1$, the absence of immature cells (blasts, promyelocytes, myelocytes), and disappearance of all signs and symptoms related to leukaemia including palpable splenomegaly. Cytogenetic response was categorised by the proportion of Ph-positive metaphases as complete $(0 \% \mathrm{Ph}+$ cells $)$, partial $(1-35 \% \mathrm{Ph}+$ cells $)$, minor $(36-65 \% \mathrm{Ph}+$ cells), minimal $(66-95 \% \mathrm{Ph}+$ cells), and none (96\%-100\% Ph+ cells). Molecular response was defined as major (MMoR) if the BCR$\mathrm{ABL}$ ratio was less than $0.10 \%$ on the International Scale (IS), where 0.10 is equal to a $3-\log$ reduction from a standard baseline level as defined in the IRIS study [24].

\section{Morphometric analysis}

For morphometric analysis of the microvascular structures, representative bone marrow biopsies were fixed in formalin, decalcified with EDTA/ $\mathrm{HCl}$, and embedded in paraffin. Haematoxylin and eosin (HE)stained and reticulin-stained slides were analysed in order to determine the number of megakaryocytes and the degree of fibrosis. For each of the samples ( $4 \mu \mathrm{m}$ thick), compositions were prepared for immu- 
nohistochemical identification of the microvascular endothelial cells that were stained with mouse monoclonal antibody CD34 (clone QBEnd 10; Dako, Carpinteria, CA, USA), as the endothelial antigen of choice for the proper identification of microvessels. The antibody CD34 was applied at a dilution of $1: 50$. In accordance with the results of other investigators, immunohistochemical staining was performed using standard streptavidin peroxidase methods [25]. Brown coloured endothelial cells or clusters, with or without a lumen, which were clearly separated from adjacent microvessels were taken as countable microvessels, respecting the previously published consensus [26]. Arterioles were not analysed. Progenitor cells were also strongly positively stained with CD34 antibody and were easily distinguishable from endothelial cells so they were used as controls to verify the adequacy of the staining.

Microscope samples were analysed with a Leica DMR microscope with a digital camera using direct digitisation. The images were first analysed at $200 \times$ magnification to identify the areas that showed the most intense vascularisation, so-called "hot spots" [27]. Consequently, these areas of "hot spots" were then evaluated at a magnification of $400 \times$, and the microvascular structure was analysed. Quantification of the digital images was performed using ImageJ software (National Institutes of Health, USA, http://rsbweb.nih.gov/ij/) on a personal computer.

Microvascular density (MVD) was quantified as the total number of microvascular structures per field of magnification (400×), HPF (high-power field), within an average unit area of $0.5 \mathrm{~mm}^{2}$. For each countable microvessel, the following size-related and shape-related morphometric parameters were determined: major axis (the distance between the two points along the vessel periphery that were farthest apart), minor axis (the longest axis perpendicular to major axis formed by two points along the vessel periphery), area (area of the micro vessel expressed in calibrated square units), perimeter (perimeter of the length of the line which is limited selected vessel), Feret diameter (longest distance between any two points along the border od the selected vessel), circularity ( $[4 \pi \times$ area $] /$ perimeter $\left.^{2}\right)$, aspect ratio (major axis/minor axis), roundness $(4 \times a r e a) /\left(\pi \times\right.$ major axis $\left.^{2}\right)$ and solidity (area/convex area). The variables entered into the statistical analysis were the total count of microvessels per optical field (MVD) and mean values of the above 10 morphologic indices.

\section{Statistical analysis}

The results, presented in tables and graphs, were analysed according to the methodology of descriptive and analytical statistics. Statistical calculations were performed in STATA 12 software (StataCorp LP, USA). Descriptive statistical analyses were presented in the form of measures of central tendency (median and interquartile range) or in the form of relative numbers (percentage). The values were shown in the form of $95 \%$ confidence intervals (CI). Potential connections of predictors of the outcome were analysed by Wilcoxon's rank sum test (Mann-Whitney U test) for continuous and ordinal variables, while the other variables used Pearson's c ${ }^{2}$ test or Fisher's exact test. Differences were considered to be statistically significant when $\mathrm{p}<0.01$.

\section{Results}

\section{Clinical and laboratory characteristics of CML patients}

A total of 40 adult patients with CML in early chronic phase, who received imatinib as first-line therapy, were analysed. The median age at diagnosis was 53.78 years (range 29-75), and 55\% were female. Baseline values of the patients with CML are summarised in Table I.

The median time from diagnosis to TKIs therapy was 1.8 months (range 0-6 months); 35 (87.5\%) patients received previous cytoreduction therapy. The median follow-up period of the surviving patients was 43.25 months (range 7-66 months). The best observed CCgR rates at 12, 24, and 36 months after initiation of imatinib were $72.5 \%, 75 \%$, and $80 \%$, respectively. In the current follow-up, only $6.25 \%$ of the 32 patients who achieved a $\mathrm{CCgR}$ had an event during treatment. An MMoR was achieved in 20 patients, in $57.14 \%$ of patients with $\mathrm{CCgR}$ and in $50 \%$ of all patients treated. According to the EURO score, $45 \%$ of the patients were at low risk, $50 \%$ at intermediate risk, and 5\% at the high risk. The percentages of patients with low, intermediate, and high Sokal risk scores were $40 \%, 45 \%$, and $15 \%$, respectively.

\section{Comparison of morphometric parameters between CML and control groups}

In this paper, different morphometric characteristics of small blood vessels in bone marrow biopsy samples of patients with CML and controls were evaluated, as shown in Table II.

Value of MVD and size-related morphometric parameters, namely length of major and minor axis, area, perimeter, and ferret diameter, were higher in the chronic phase of CML than in the control group $(\mathrm{p}<0.01)$. The control group showed lower values of shape-related morphometric parameters of circularity, roundness, and solidity of blood vessels, and higher values of aspect ratio $(p<0.01)$. Differences were observed in increased vessel density with large-calibre blood vessel and tortuosity and branching of the vascular structures of the bone marrow of 
Table I. Clinical and laboratory characteristics of the patients with chronic myeloid leukaemia

\begin{tabular}{|c|c|c|c|}
\hline PARAmeter & $\mathbf{N}$ & MEDian & RANGE \\
\hline Age & 40 & 53.78 years & $29-75$ years \\
\hline Gender (male/female) & $18 / 22$ & & \\
\hline Palpable spleen size*(yes/no) & $25 / 15$ & $5.28 \mathrm{~cm}$ & $0-21 \mathrm{~cm}$ \\
\hline \multicolumn{4}{|l|}{ Baseline laboratory values } \\
\hline WBC count & & $135.55 \times 10^{9} / 1$ & $20-483 \times 10^{9} / 1$ \\
\hline PLT count*(normal/increase) & $24 / 16$ & & \\
\hline Haemoglobin*(decrease/normal) & $25 / 15$ & & \\
\hline Peripheral blasts & & $1.96 \%$ & $0-5.5 \%$ \\
\hline Peripheral basophils & & $3.50 \%$ & $0-7 \%$ \\
\hline Peripheral eosinophils & & $2.60 \%$ & $0-7.5 \%$ \\
\hline \multicolumn{4}{|l|}{ Baseline bone marrow histology } \\
\hline $\begin{array}{l}\text { Megakaryocytes } \\
\text { (not increased/increased) }\end{array}$ & $22 / 18$ & & \\
\hline $\begin{array}{l}\text { Reticulin fibrosis } \\
\text { grade } 0 / \text { grade } 1 / \text { grade } 2-3\end{array}$ & $27 / 10 / 3$ & & \\
\hline
\end{tabular}

Table II. Evaluation of vascular morphometric parameters in patients with chronic myeloid leukaemia and the control group

\begin{tabular}{|c|c|c|c|c|}
\hline MORPHOMETRIC PARAMETERS & $\begin{array}{c}\text { CML } \\
(\mathrm{N}=40) \\
(\text { MEDIAN, IQR) }\end{array}$ & $\begin{array}{c}\text { ConTROLS } \\
(\mathrm{N}=20) \\
(\text { MEDIAN, IQR) }\end{array}$ & \multicolumn{2}{|c|}{$\begin{array}{l}\text { WILCOXON RANK-SUM } \\
\text { (MANN-WHITNEY) TEST }\end{array}$} \\
\hline MVD (n/HPF) & $8.7(7-10.7)$ & $3.5(3-4.2)$ & $\mathrm{z}$ & $\mathrm{p}$ \\
\hline Major axis $(\mu \mathrm{m})$ & $31.7(27.4-39.7)$ & $22.3(20.1-23.3)$ & 5.495 & 0.00 \\
\hline Minor axis $(\mu \mathrm{m})$ & $9.8(7.4-12.9)$ & $5.2(4.3-5.5)$ & 5.818 & 0.00 \\
\hline Area $(\mu 2 \mathrm{~m})$ & $258(169.4-421.7)$ & $90.5(70.5-108.3)$ & 5.567 & 0.00 \\
\hline Perimeter $(\mu \mathrm{m})$ & $84.9(70.7-103.9)$ & $57.9(52.8-61.1)$ & 4.375 & 0.00 \\
\hline Feret diameter $(\mu \mathrm{m})$ & $34.6(29.9-42.8)$ & $25.3(23.4-27.6)$ & 3.920 & 0.00 \\
\hline Circularity & $0.48(0.43-0.60)$ & $0.37(0.3-0.46)$ & 3.748 & 0.00 \\
\hline Aspect ratio & $3.7(3-4.4)$ & $5.04(4.6-6.15)$ & -4.062 & 0.00 \\
\hline Roundness & $0.35(0.3-0.43)$ & $0.26(0.22-0.34)$ & 3.254 & $<0.01$ \\
\hline Solidity & $0.81(0.77-0.87)$ & $0.79(0.75-0.85)$ & 2.933 & $<0.01$ \\
\hline
\end{tabular}

CML, as opposed to a decreased vessel density with simple and straight microvessels in the control group. The findings indicate significantly increased vascularity in CML in comparison to the control group.

\section{Correlation of morphometric parameters to cytogenetic and molecular response}

In the current study, we investigated whether bone marrow angiogenesis at diagnosis of CML can predict the level of therapeutic response and the possibility of achieving CCgR and MMoR (Tables III, IV).

A statistically significant correlation was established between achievement of $\mathrm{CCgR}$ and the value of MVD (eta $=0.442)$ and size-related morphometric parameters: the length of the minor axis $($ eta $=0.651)$ and area (eta $=0.553$ ) of the blood vessel. Also, a statistically significant correlation was found between achievement of $\mathrm{CCgR}$ and shape-related morphometric parameters: circularity (eta $=0.570)$, roundness (eta $=0.529)$, and solidity (eta $=0.569)$, as well as statistically significant correlation with the aspect ratio (eta $=0.570$ ) of the microvessels.

In Fig. 1 bone marrow samples of CML patients with different therapeutic response are shown.

There are a smaller number of microvessels having a smaller area in the CML patients who achieved the optimal therapeutic response, $\mathrm{CCgR}$ plus $\mathrm{MMoR}$ (Fig. 1A, B), versus a greater number of vessels of 
Table III. Analysis of variance (ANOVA) and correlation of complete cytogenetic response and angiogenesis parameters

\begin{tabular}{|c|c|c|c|c|c|c|c|}
\hline \multirow{2}{*}{$\begin{array}{l}\text { MORPHOMETRIC } \\
\text { PARAMETERS }\end{array}$} & \multicolumn{7}{|c|}{ CCGR ( 1 - RESPONDERS; 0 - NONRESPONDERS $)(\mathrm{N}=40)$} \\
\hline & & $\begin{array}{c}\text { Sum } \\
\text { OF SQUARES }\end{array}$ & DF & $\begin{array}{l}\text { MEAN } \\
\text { SQUARE }\end{array}$ & $\mathrm{F}$ & $\begin{array}{l}\text { ETA CORRELATION } \\
\text { COEFFICIENT }\end{array}$ & $\mathbf{P}$ \\
\hline \multirow{3}{*}{ MVD (n/HPF) } & Between groups & 79.338 & 1 & 79.338 & \multirow{3}{*}{9.218} & \multirow{3}{*}{0.442} & \multirow{3}{*}{0.004} \\
\hline & Within groups & 327.043 & 38 & 8.606 & & & \\
\hline & Total & 406.381 & 39 & & & & \\
\hline \multirow{3}{*}{ Major axis $(\mu \mathrm{m})$} & Between groups & 257.795 & 1 & 257.795 & \multirow{3}{*}{3.856} & \multirow{3}{*}{0.304} & \multirow{3}{*}{0.057} \\
\hline & Within groups & 2540.407 & 38 & 66.853 & & & \\
\hline & Total & 2798.202 & 39 & & & & \\
\hline \multirow{3}{*}{ Minor axis $(\mu \mathrm{m})$} & Between groups & 226.007 & 1 & 226.007 & \multirow{3}{*}{27.936} & \multirow{3}{*}{0.651} & \multirow{3}{*}{0.000} \\
\hline & Within groups & 307.422 & 38 & 8.090 & & & \\
\hline & Total & 533.429 & 39 & & & & \\
\hline \multirow{3}{*}{ Area $\left(\mu^{2} \mathrm{~m}\right)$} & Between groups & 381965.320 & 1 & 381965.320 & \multirow{3}{*}{16.764} & \multirow{3}{*}{0.553} & \multirow{3}{*}{0.000} \\
\hline & Within groups & 865817.405 & 38 & 22784.669 & & & \\
\hline & Total & 1247782.725 & 39 & & & & \\
\hline \multirow{3}{*}{ Perimeter $(\mu \mathrm{m})$} & Between groups & 1835.518 & 1 & 1835.518 & \multirow{3}{*}{3.929} & \multirow{3}{*}{0.306} & \multirow{3}{*}{0.055} \\
\hline & Within groups & 17754.593 & 38 & 467.226 & & & \\
\hline & Total & 19590.111 & 39 & & & & \\
\hline \multirow{3}{*}{$\begin{array}{l}\text { Feret } \\
\text { diameter }(\mu \mathrm{m})\end{array}$} & Between groups & 194.425 & 1 & 194.425 & \multirow{3}{*}{2.309} & \multirow{3}{*}{0.239} & \multirow{3}{*}{0.137} \\
\hline & Within groups & 3200.125 & 38 & 84.214 & & & \\
\hline & Total & 3394.550 & 39 & & & & \\
\hline \multirow{3}{*}{ Circularity } & Between groups & 0.117 & 1 & 0.117 & \multirow{3}{*}{18.301} & \multirow{3}{*}{0.570} & \\
\hline & Within groups & 0.242 & 38 & 0.006 & & & 0.000 \\
\hline & Total & 0.359 & 39 & & & & \\
\hline & Between groups & 8.175 & 1 & 8.175 & & & \\
\hline Aspect ratio & Within groups & 17.003 & 38 & 0.447 & 18.271 & 0.570 & 0.000 \\
\hline & Total & 25.178 & 39 & & & & \\
\hline & Between groups & 0.066 & 1 & 0.066 & & & \\
\hline Roundness & Within groups & 0.171 & 38 & 0.004 & 14.785 & 0.529 & 0.000 \\
\hline & Total & 0.237 & 39 & & & & \\
\hline Solidity & Between groups & 0.044 & 1 & 0.044 & 18.194 & 0.569 & 0.000 \\
\hline & Within groups & 0.092 & 38 & 0.002 & & & \\
\hline & Total & 0.135 & 39 & & & & \\
\hline
\end{tabular}

large calibre and irregular shapes with the CML patients with the absence of therapeutic response to the TKIs (Fig. 1C, D).

\section{Prognostic morphometric parameters that} influence the achievement of CCgR and MMoR

To determine whether the degree of bone marrow angiogenesis at diagnosis may predict treatment outcome of patients with CML, association between morphometric parameters and achievement of an optimal therapeutic response was examined. Association between the morphometric parameters and the possibility of later achieving cytogenetic and molecular response during treatment is shown in Tables V, VI.

In relation to achieved $\mathrm{CCgR}$, univariate analysis identified the following relevant morphometric parameters: value of MVD less than 9/HPF, length of the minor axis less than $10 \mu \mathrm{m}$, area less than $350 \mu \mathrm{m}^{2}$, circularity less than 0.5 , aspect ratio higher than 3.5, and roundness of blood vessel less than 0.35 , as independent prognostic factors for achieving this level of response $(\mathrm{p}<0.01)$. 

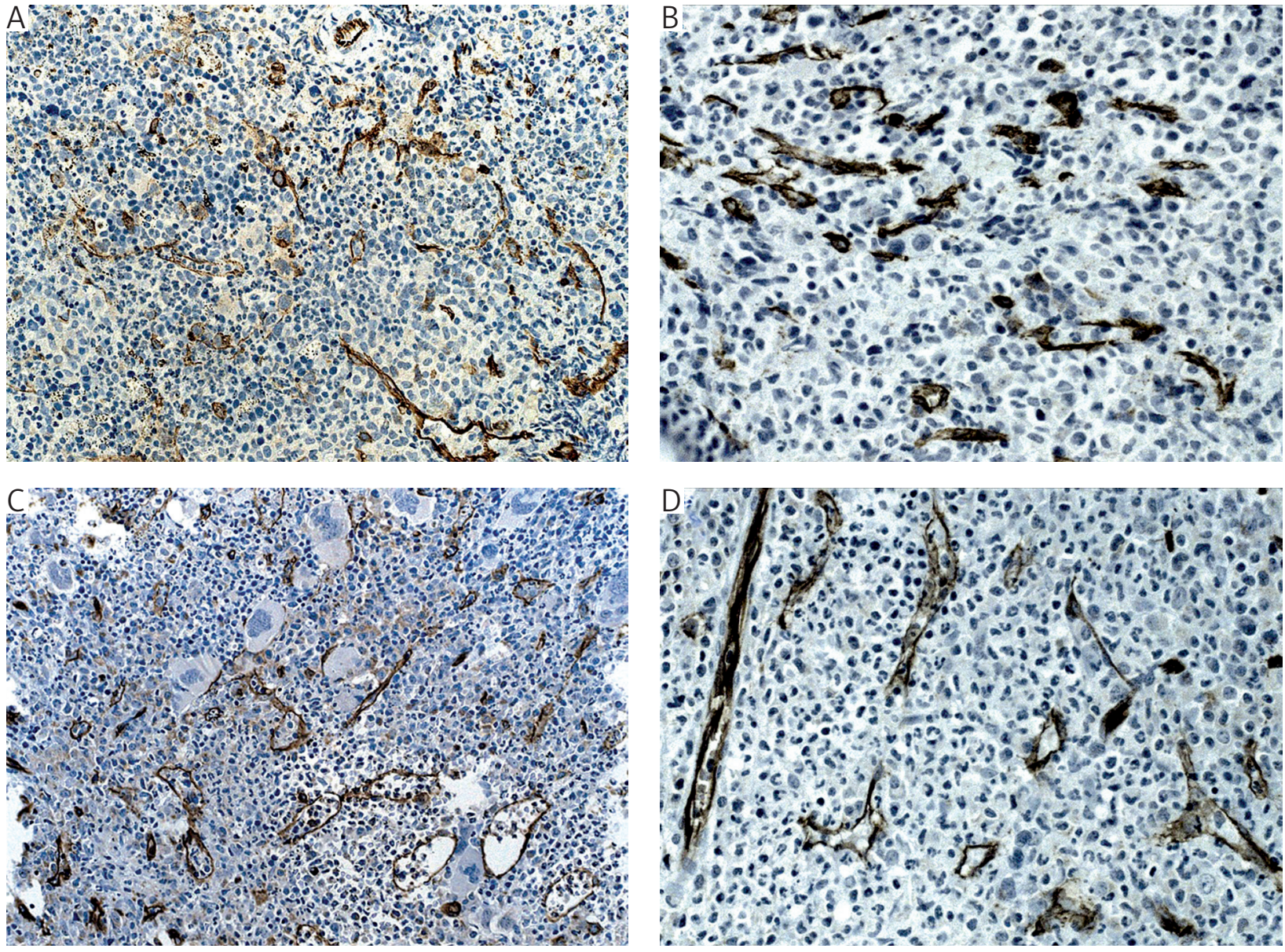

Fig. 1. Immunohistochemical staining of bone marrow endothelial cells for CD34 in CML at diagnosis in the case of CML patients who achieved optimal therapeutic response on therapy (A, B), and in the case of CML patients with absent therapeutic response (C, D). A, C) 200×; B, D) 400×

Among patients with value of MVD less than 9/HPF and length of the minor axis less than $10 \mu \mathrm{m}, 66.77 \%$ achieved $\mathrm{CCgR}$, while among patients with a higher level of these variables, $33.33 \%$ achieved the same level of response in the analysed period. There was a significantly higher percentage of patients who achieved $\mathrm{CCgR}$ in the group with area of the blood vessel less than $350 \mu \mathrm{m}^{2}(75.67 \%)$, compared to the group of patients with higher values of this parameter (23.33\%). Patients with values of circularity less than 0.5 and aspect ratio greater than 3.5, in $70 \%$ of cases achieved $\mathrm{CCgR}$, while in case of roundness less than 0.35 this level of response was achieved in $63.33 \%$ of patients.

According to the statistical analysis, among 10 analysed morphometric parameters, value of MVD less than 9/HPF ( $p<0.01$ ) was identified as an independent prognostic factor for achieving MMoR. From the group of patients with value of MVD less than 9/HPF as much as $80 \%$ of patients achieved MMoR.

\section{Discussion}

Increased angiogenesis in bone marrow is one of the characteristics of CML. The role of angiogene- sis in the pathogenesis of CML was confirmed by the effects of the BCR-ABL mutation on the expression and secretion of the angiogenic factors, VEGF, and another angiogenic cytokines like bFGF, hepatocyte growth factor, interleukin-8, and matrix metalloproteinases, by tumour cells and bone marrow stromal cells $[28,29]$. Furthermore, studies have shown that normal and BCR-ABL expressing bone marrow-derived endothelial cells were able to contribute to maintenance of angiogenesis in the vascular endothelium, although their origin remains elusive $[30,31]$.

Imatinib was developed as a target inhibitor for the protein BCR-ABL tyrosine kinase [32], and it has become the gold standard in the treatment of CML [33]. Further studies showed that imatinib reduces the BCR-ABL-mediated secretion of VEGF [21] and leads to a decrease in VEGF production in CML with resulting inhibition of VEGF gene transcription, which are the main reasons for the antiangiogenic effects of this drug [34]. Imatinib also selectively inhibits growth of primitive malignant progenitors, but does not significantly increase apoptosis [35]. During treatment with imatinib, bone marrow changes showed normalisation of erythropoiesis accompanied 
Table IV. Analysis of variance (ANOVA) and correlation of major molecular response and angiogenesis parameters

\begin{tabular}{|c|c|c|c|c|c|c|c|}
\hline \multirow{4}{*}{$\begin{array}{l}\text { MORPHOMETRIC } \\
\text { PARAMETERS }\end{array}$} & \multicolumn{7}{|c|}{ MMOR (1-RESPONDERS; 0-NONRESPONDERS) $\mathrm{N}=35$} \\
\hline & & SUM OF & $\mathrm{DF}$ & Mean SQuare & $\mathrm{F}$ & ETA & $\mathbf{P}$ \\
\hline & & SQUARES & & & & CORRELATION & \\
\hline & & & & & & COEFFICIENT & \\
\hline \multirow{3}{*}{ MVD (n/HPF) } & Between groups & 102.656 & 1 & 102.656 & \multirow{3}{*}{12.844} & \multirow{3}{*}{0.503} & \multirow{3}{*}{0.001} \\
\hline & Within groups & 303.725 & 38 & 7.993 & & & \\
\hline & Total & 406.381 & 39 & & & & \\
\hline \multirow{3}{*}{ Major axis $(\mu \mathrm{m})$} & Between groups & 441.337 & 1 & 441.337 & \multirow{3}{*}{7.116} & \multirow{3}{*}{0.397} & \multirow{3}{*}{0.011} \\
\hline & Within groups & 2356.865 & 38 & 62.023 & & & \\
\hline & Total & 2798.202 & 39 & & & & \\
\hline \multirow{3}{*}{ Minor axis $(\mu \mathrm{m})$} & Between groups & 172.552 & 1 & 172.552 & \multirow{3}{*}{18.170} & \multirow{3}{*}{0.569} & \multirow{3}{*}{0.000} \\
\hline & Within groups & 360.877 & 38 & 9.497 & & & \\
\hline & Total & 533.429 & 39 & & & & \\
\hline \multirow{3}{*}{ Area $\left(\mu^{2} \mathrm{~m}\right)$} & Between groups & 335198.069 & 1 & 335198.069 & \multirow{3}{*}{13.958} & \multirow{3}{*}{0.518} & \multirow{3}{*}{0.001} \\
\hline & Within groups & 912584.656 & 38 & 24015.386 & & & \\
\hline & Total & 1247782.725 & 39 & & & & \\
\hline \multirow{3}{*}{ Perimeter $(\mu \mathrm{m})$} & Between groups & 3373.953 & 1 & 3373.953 & \multirow{3}{*}{7.906} & \multirow{3}{*}{0.415} & \multirow{3}{*}{0.008} \\
\hline & Within groups & 16216.157 & 38 & 426.741 & & & \\
\hline & Total & 19590.111 & 39 & & & & \\
\hline \multirow{3}{*}{ Feret diameter $(\mu \mathrm{m})$} & Between groups & 455.751 & 1 & 455.751 & \multirow{3}{*}{5.893} & \multirow{3}{*}{0.366} & \multirow{3}{*}{0.020} \\
\hline & Within groups & 2938.799 & 38 & 77.337 & & & \\
\hline & Total & 3394.550 & 39 & & & & \\
\hline \multirow{3}{*}{ Circularity } & Between groups & 0.046 & 1 & 0.046 & \multirow{3}{*}{5.604} & & \\
\hline & Within groups & 0.313 & 38 & 0.008 & & 0.359 & 0.023 \\
\hline & Total & 0.359 & 39 & & & & \\
\hline & Between groups & 3.605 & 1 & 3.605 & & & \\
\hline Aspect ratio & Within groups & 21.573 & 38 & 0.568 & 6.349 & 0.378 & 0.016 \\
\hline & Total & 25.178 & 39 & & & & \\
\hline & Between groups & 0.036 & 1 & 0.036 & & & \\
\hline Roundness & Within groups & 0.202 & 38 & 0.005 & 6.716 & 0.388 & 0.013 \\
\hline & Total & 0.237 & 39 & & & & \\
\hline Solidity & Between groups & 0.010 & 1 & 0.010 & 2.967 & 0.269 & 0.093 \\
\hline & Within groups & 0.126 & 38 & 0.003 & & & \\
\hline & Total & 0.135 & 39 & & & & \\
\hline
\end{tabular}

by marked reduction of granulocytes and megakaryocytes and impressive regression of fibre content [36]. Besides the fact that the marrow fibrosis reduces during the duration of imatinib therapy, it was found that the degree of marrow fibrosis at diagnosis has no negative impact on the therapeutic response to imatinib therapy [37], while other studies reported the opposite [38, 39]. Also, it was determined that imatinib leads to a decrease in the initially enhanced MVD combined with a decrease in luminal distension [40].
Higher values of MVD in CML patients in chronic phase compared to normal controls were clearly demonstrated in our study, which is consistent with previously published studies [13, 14, 20]. Moreover, Aguayo et al. [13] showed that the highest number of blood vessels and the largest vascular area were seen in patients with CML in comparison to other acute and chronic leukaemias and myelodysplastic syndromes. A study by Lundberg et al. [14] demonstrated that among chronic myeloproliferative disease 
Table V. Parameters of angiogenesis associated with achieving complete cytogenetic response

\begin{tabular}{|c|c|c|c|c|}
\hline \multirow{2}{*}{$\begin{array}{l}\text { MORPHOMETRIC } \\
\text { PARAMETERS }\end{array}$} & \multicolumn{3}{|c|}{ CCGR } & \multirow[b]{2}{*}{$\mathbf{P}$} \\
\hline & $\begin{array}{c}\text { No } \\
(\mathrm{N}=10)\end{array}$ & $\begin{array}{c}\text { YES } \\
(\mathrm{N}=30)\end{array}$ & $\begin{array}{l}\text { IN TOTAL } \\
(\mathrm{N}=40)\end{array}$ & \\
\hline MVD (n/HPF) & $10.5(9.3-12)$ & $8.5(5-9.67)$ & $8.71(7-10.67)$ & 0.0044 \\
\hline$<9$ & $1(10 \%)$ & $20(66.7 \%)$ & $21(52.5 \%)$ & \\
\hline$\geq 9$ & $9(90 \%)$ & $10(33.33 \%)$ & $19(47.5 \%)$ & 0.002 \\
\hline Major axis $(\mu \mathrm{m})$ & $37.72(33.6-42.2)$ & $29.8(26.9-37.01)$ & $31.72(27.4-39.7)$ & 0.0393 \\
\hline$<35$ & $3(30 \%)$ & $20(66.7 \%)$ & $23(57.5 \%)$ & \\
\hline$\geq 35$ & $7(70 \%)$ & $10(33.33 \%)$ & $17(42.5 \%)$ & 0.049 \\
\hline Minor axis $(\mu \mathrm{m})$ & $15.26(13.06-16.95)$ & $8.85(7.37-10.46)$ & $9.76(7.44-12.89)$ & 0.0002 \\
\hline$<10$ & $1(10 \%)$ & $20(66.7 \%)$ & $21(52.5 \%)$ & \\
\hline$\geq 10$ & $9(90 \%)$ & $10(33.33 \%)$ & $19(47.5 \%)$ & 0.002 \\
\hline Area $\left(\mu^{2} \mathrm{~m}\right)$ & $437.8(413.1-633.6)$ & $213.8(159.9-348.5)$ & $258(169.4-421.7)$ & 0.0012 \\
\hline$<350$ & $1(10 \%)$ & $23(75.67 \%)$ & $24(60 \%)$ & \\
\hline$\geq 350$ & $9(90 \%)$ & $7(23.33 \%)$ & $16(40 \%)$ & 0.000 \\
\hline Perimeter $(\mu \mathrm{m})$ & $100.8(89.4-110.9)$ & $76.5(70-95.3)$ & $84.9(70.7-103.9)$ & 0.0423 \\
\hline$<85$ & $2(20 \%)$ & $18(60 \%)$ & $20(50 \%)$ & \\
\hline$\geq 85$ & $8(80 \%)$ & $12(40 \%)$ & $20(50 \%)$ & 0.032 \\
\hline Feret diameter $(\mu \mathrm{m})$ & $40.9(35.4-47)$ & $32.1(29.4-41.4)$ & $34.6(29.9-42.8)$ & 0.0858 \\
\hline$<40$ & $5(50 \%)$ & $22(73.33 \%)$ & $27(67.5 \%)$ & \\
\hline$\geq 40$ & $5(50 \%)$ & $8(26.67 \%)$ & $13(32.5 \%)$ & 0.165 \\
\hline Circularity & $0.61(0.54-0.65)$ & $0.45(0.42-0.57)$ & $0.48(0.43-0.60)$ & 0.0003 \\
\hline$<0.5$ & $1(10 \%)$ & $21(70 \%)$ & $22(55 \%)$ & \\
\hline$\geq 0.5$ & $9(90 \%)$ & $9(30 \%)$ & $18(45 \%)$ & 0.001 \\
\hline Aspect ratio & $2.73(2.64-3.15)$ & $3.98(3.45-4.53)$ & $3.68(2.95-4.36)$ & 0.0007 \\
\hline$<3.5$ & $9(90 \%)$ & $9(30 \%)$ & $18(45 \%)$ & \\
\hline$\geq 3.5$ & $1(10 \%)$ & $21(70 \%)$ & $22(65 \%)$ & 0.001 \\
\hline Roundness & $0.43(0.39-0.48)$ & $0.32(0.29-0.39)$ & $0.35(0.30-0.43)$ & 0.0009 \\
\hline$<0.35$ & $0(0 \%)$ & $19(63.33 \%)$ & $19(47.5 \%)$ & \\
\hline$\geq 0.35$ & $10(100 \%)$ & $11(36.67 \%)$ & $21(52.5 \%)$ & 0.000 \\
\hline Solidity & $0.89(0.85-0.91)$ & $0.79(0.76-0.85)$ & $0.80(0.77-0.87)$ & 0.0004 \\
\hline$<0.77$ & $0(0 \%)$ & $11(36.67 \%)$ & $11(27.5 \%)$ & \\
\hline$\geq 0.77$ & $10(100 \%)$ & $19(63.33 \%)$ & $29(72.5 \%)$ & 0.024 \\
\hline
\end{tabular}

Mann-Whitney $U$ test for continuous variables or Fisher's test and Pearson c2 test for the other variables

(MPD), CML and myelofibrosis (MF) were associated with increased microvessel density and revealed tortuous microvessel architecture and increased branching in bone marrow in comparison to the control group. Korkolopoulou et al. [20] also confirmed that the group of chronic phase CML had higher MVD than controls, but also demonstrated higher value of size-related parameters and higher degree of microvessels branching in CML group. These findings indicate that angiogenesis is prominent in chronic phase CML as a result of the formation of large sinusoidal space. For the first time, it was shown that the prognostic significance of angiogenesis in CML could be better assessed by the size of small blood vessels, while MVD was influential only in terms of survival.

These results agree with the results of our research, which established that in addition to the MVD, all analysed size- and shape-related parameters were 
Table VI. Parameters of angiogenesis associated with achieving major molecular response

\begin{tabular}{|c|c|c|c|c|}
\hline \multirow{2}{*}{$\begin{array}{l}\text { MORPHOMETRIC } \\
\text { PARAMETERS }\end{array}$} & \multicolumn{3}{|c|}{ MMoR } & \multirow[b]{2}{*}{$\mathbf{P}$} \\
\hline & $\begin{array}{c}\text { No } \\
(\mathrm{N}=15)\end{array}$ & $\begin{array}{c}\text { Yes } \\
(\mathrm{N}=20)\end{array}$ & $\begin{array}{l}\text { IN TOTAL } \\
(\mathrm{N}=35)\end{array}$ & \\
\hline MVD (n/HPF) & $10.67(8.67-12)$ & $7.67(4.67-8.67)$ & $8.67(5.33-10.67)$ & 0.0021 \\
\hline$<9$ & $4(26.67 \%)$ & $16(80 \%)$ & $20(57.14 \%)$ & \\
\hline$\geq 9$ & $11(73.33 \%)$ & $4(20 \%)$ & $15(42.86 \%)$ & 0.002 \\
\hline Major axis $(\mu \mathrm{m})$ & $35.6(30.28-41.43)$ & $28.39(24.4-36.2)$ & $30.9(27.1-37.9)$ & 0.0150 \\
\hline$<35$ & $7(46.67 \%)$ & $14(70 \%)$ & $21(60 \%)$ & \\
\hline$\geq 35$ & $8(53.33 \%)$ & $6(30 \%)$ & $14(40 \%)$ & 0.148 \\
\hline Minor axis $(\mu \mathrm{m})$ & $10.8(9.6-13.2)$ & $7.8(6.7-10)$ & $9.6(7.4-11.4)$ & 0.0019 \\
\hline$<10$ & $5(33.33 \%)$ & $15(75 \%)$ & $20(57.14 \%)$ & \\
\hline$\geq 10$ & $10(67.67 \%)$ & $5(25 \%)$ & $15(42.86 \%)$ & 0.017 \\
\hline Area $(\mu 2 \mathrm{~m})$ & $364.9(235-434)$ & $177.8(127.9-304.1)$ & $235(161.4-401.2)$ & 0.0015 \\
\hline$<350$ & $7(46.67 \%)$ & $16(80 \%)$ & $23(65.71 \%)$ & \\
\hline$\geq 350$ & $8(53.33 \%)$ & $4(20 \%)$ & $12(34.29 \%)$ & 0.045 \\
\hline Perimeter $(\mu \mathrm{m})$ & $91(77.8-106.8)$ & $71.7(64.2-94.6)$ & $77.8(70-100.3)$ & 0.0077 \\
\hline$<85$ & $5(33.33 \%)$ & $14(70 \%)$ & $19(54.29 \%)$ & \\
\hline$\geq 85$ & $10(67.67 \%)$ & $6(30 \%)$ & $16(45.71 \%)$ & 0.034 \\
\hline Feret diameter $(\mu \mathrm{m})$ & $39.7(33.7-45.9)$ & $31.1(27.7-39.6)$ & $33.7(29.6-41.5)$ & 0.0234 \\
\hline$<40$ & $10(67.67 \%)$ & $15(75 \%)$ & $25(71.43 \%)$ & \\
\hline$\geq 40$ & $5(33.33 \%)$ & $5(25 \%)$ & $10(28.57 \%)$ & 0.433 \\
\hline Circularity & $0.51(0.43-0.61)$ & $0.46(0.42-0.53)$ & $0.47(0.43-0.58)$ & 0.1425 \\
\hline$<0.5$ & $7(46.67 \%)$ & $15(75 \%)$ & $22(62.86 \%)$ & \\
\hline$\geq 0.5$ & $8(53.33 \%)$ & $5(25 \%)$ & $13(37.14 \%)$ & 0.087 \\
\hline Aspect ratio & $3.67(2.73-4.27)$ & $3.98(3.47-4.58)$ & $3.76(3.11-4.41)$ & 0.1425 \\
\hline$<3.5$ & $7(46.67 \%)$ & $6(30 \%)$ & $13(37.14)$ & \\
\hline$\geq 3.5$ & $8(53.33 \%)$ & $14(70 \%)$ & $22(62.86 \%)$ & 0.255 \\
\hline Roundness & $0.39(0.31-0.45)$ & $0.33(0.3-0.36)$ & $0.34(0.3-0.43)$ & 0.1096 \\
\hline$<0.35$ & $5(33.33 \%)$ & $14(70 \%)$ & $19(54.29 \%)$ & \\
\hline$\geq 0.35$ & $10(67.67 \%)$ & $6(30 \%)$ & $16(45.71 \%)$ & 0.034 \\
\hline Solidity & $0.81(0.76-0.85)$ & $0.79(0.76-0.85)$ & $0.80(0.76-0.85)$ & 0.6648 \\
\hline$<0.77$ & $5(33.33 \%)$ & $6(30 \%)$ & $11(31.43 \%)$ & \\
\hline$\geq 0.77$ & $10(67.67 \%)$ & $14(70 \%)$ & $24(68.57 \%)$ & 0.560 \\
\hline
\end{tabular}

significantly higher in chronic phase CML as compared to the control group. In the present study differences were also observed in the bone marrow vasculature among CML patients in relation to level of therapeutic response. An increased number of microvessels was noticed with larger microvessel area and more pronounced irregularity of shape in CML patients with absent therapeutic response, as opposed to a lower number of microvessels with smaller area and with rare irregularity of shape in CML patients achieving optimal therapeutic response.
To the best of our knowledge, this research is the first in the literature to examine the prognostic significance of various morphometric variables of $\mathrm{mi}$ crovessels in relation to the achievement of $\mathrm{CCgR}$ and $\mathrm{MMoR}$ as indicators of clinical outcome in CML patients treated with imatinib. Statistical analysis has separated lower values of MVD, minor axis, area, circularity, and roundness as well as higher aspect ratio of the blood vessel as significant positive prognostic factors for achieving $\mathrm{CCgR}$. Regarding the possibility of achieving an MMoR, only lower value of MVD 
has been identified as a positive prognostic factor with statistical significance for achieving this level of response. In contrast to that, Rumpel et al. [41] have shown that imatinib normalises bone marrow vascularity in the majority of patients with chronic phase CML, while a clear correlation with cytogenetic response has not been proven. Korkolopoulou et al. [20] reported that increased bone marrow angiogenesis appears to have prognostic significance in the outcome of CML, predicting both disease progression and survival during therapy. The authors [20] showed that among morphometric parameters univariate analysis identified that MVD, minor axis, area, and TVA (total vascular area) were the parameters that had a negative impact on time to progression and with regard to survival, while fibrosis of the bone core reached boundary significance in this regard. However, multivariate analysis indicated that microvessel area was related to progression-free survival, whereas both MVD and area were significant prognostic factors of overall survival. In our previous work [42] we showed that the use of morphometric parameters of angiogenesis, available at diagnosis of $\mathrm{CML}$, may improve prediction of $\mathrm{CCgR}$ at 6,12 , and 18 months on imatinib therapy when added to standard EUTOS prognostic scoring system in comparison to usage of EUTOS score alone. In this paper, the prognostic significance of angiogenesis for predicting optimal therapeutic response has been established.

In conclusion, our data confirmed the presence of increased angiogenesis in the CML and a high degree of optimal therapeutic response due to the potential value of additional anti-angiogenesis effect of imatinib. This research demonstrated the prognostic significance of the degree of angiogenesis, microvascular density, and the number of different size- and shape-related parameters of microvessels on clinical outcome in chronic myeloid leukaemia. More importantly, our study identified for the first time morphometric predictive factors for achieving a complete cytogenetic and major molecular response, and suggested the need for their determination and use to improve prediction of the optimal therapeutic response, which can be reported as the main novelty of the paper.

\section{The authors declare no conflicts of interests.}

\section{References}

1. Sawyers CL. Chronic myeloid leukemia. N Engl J Med 1999; 340: 1330-1340.

2. Deininger MW, Goldman JM, Melo JV. The molecular biology of chronic myeloid leukemia. Blood 2000; 96: 3343-3356.

3. Van Etten RA. Mechanisms of transformation by the BCR-ABL oncogene: new perspectives in the post-imatinib era. Leuk Res 2004; 28 Suppl 1: S21-28.

4. Folkman J. New perspectives in clinical oncology from angiogenesis research. Eur J Cancer 1996; 32A: 2534-2539.
5. Folkman J. Angiogenesis in cancer, vascular, rheumatoid and other disease. Nat Med 1995; 1: 27-31.

6. Aguayo A, O’Brien S, Keating M, et al. Clinical relevance of intracellular vascular endothelial growth factor levels in B-cell chronic lymphocytic leukemia. Blood 2000; 96: 768-770.

7. Padró T, Ruiz S, Bieker R, et al. Increased angiogenesis in the bone marrow of patients with acute myeloid leukemia. Blood 2000; 95: 2637-2644.

8. Hussong JW, Rodgers JM, Shami PJ. Evidence of increased angiogenesis in patients with acute myeloid leukemia. Blood 2000; 95: 309-313.

9. Korkolopoulou P, Apostolidou E, Pavlopoulos PM, et al. Prognostic evaluation of the microvascular network in myelodysplastic syndromes. Leukemia 2001; 15: 1369-1376.

10. Lundberg LG, Hellstrom-Lindberg E, Kanter-Lewensohn $\mathrm{L}$, et al. Angiogenesis in relation to clinical stage, apoptosis and prognostic score in myelodysplastic syndromes. Leuk Res 2006; 30: 247-253.

11. Savić A, emerikić-Martinović V, Dovat S, et al. Angiogenesis and survival in patients with myelodysplastic syndrome. Pathol Oncol Res 2012; 18: 681-690.

12. Rajkumar SV, Leong T, Roche PC, et al. Prognostic value of bone marrow angiogenesis in multiple myeloma. Clin Cancer Res 2000; 6: 3111-3116.

13. Aguayo A, Kantarjian H, Manshouri T, et al. Angiogenesis in acute and chronic leukemias and myelodysplastic syndromes. Blood 2000; 96: 2240-2245.

14. Lundberg LG, Lerner R, Sundelin P, et al. Bone marrow in polycythemia vera, chronic myelocytic leukemia and myelofibrosis has an increased vascularity. Am J Pathol 2000; 157: 15-19.

15. Di Raimondo F, Palumbo GA, Molica S, et al. Angiogenesis in chronic myeloproliferative diseases. Acta Haematol 2001; 106: $177-183$.

16. Hochhaus A, O'Brien SG, Guilhot F, et al. Six year follow-up of patients receiving imatinib for the first-line treatment of chronic myeloid leukemia. Leukemia 2009; 23: 1054-1061.

17. Jabbour E, Kantarjian H, O'Brien S, et al. The achievement of an early complete cytogenetic response is a major determinant for outcome in patients with early chronic phase chronic myeloid leukemia treated with tyrosine kinase inhibitors. Blood 2011; 118: 4541-4546.

18. Hughes TP, Saglio G, Kantarjian HM, et al. Early molecular response predicts outcomes in patients with chronic myeloid leukemia in chronic phase treated with frontline nilotinib or imatinib. Blood 2014; 123: 1353-1360.

19. Kvasnicka HM, Thiele J, Staib P, et al. Reversal of bone marrow angiogenesis in chronic myeloid leukemia following imatinib mesylate (STI571) therapy. Blood 2004; 103: 3549-3551.

20. Korkolopoulou P, Viniou N, Kavantzas N, et al. Clinicopathologic correlations of bone marrow angiogenesis in chronic myeloid leukemia: a morphometric study. Leukemia 2003; 17: 89-97.

21. Ebos JM, Tran J, Master Z, et al. Imatinib mesylate (STI-571) reduces $\mathrm{Bcr}-\mathrm{Abl}$-mediated vascular endothelial growth factor secretion in chronic myelogenous leukemia. Mol Cancer Res 2002; 1: 89-95.

22. Baccarani M, Cortes J, Pane FD, et al. Chronic myeloid leukemia. An update of concepts and management Recommendations of the European LeukemiaNet. J Clin Oncol 2009; 27 : 6041-6051.

23. Baccarani M, Deininger MW, Rosti G, et al. European LeukemiaNet recommendations for the management of chronic myeloid leukemia: 2013. Blood 2013; 122: 872-884.

24. Hughes T, Deininger M, Hochhaus A, et al. Monitoring CML patients responding to treatment with tyrosine kinase inhibitors: review and recommendations for harmonizing current methodology for detecting $\mathrm{BCR}-\mathrm{ABL}$ transcripts and kinase 
domain mutations and for expressing results. Blood 2006; 108: 28-37.

25. Hsu SM, Raine L, Fanger L. Use of avidin-biotin-peroxidase complex $(\mathrm{ABC})$ in immunoperoxidase techniques: a comparasion between $\mathrm{ABC}$ and unlabelled antibody (PAP) procedures. J Hisohem Cytochem 1981; 29: 577-580.

26. Padro T, Ruiz S, Bieker R, et al. Increased angiogenesis in the bone marrow of patients with acute myeloid leukemia. Blood 2000; 95: 2637-2644.

27. Vermeulan PB, Gasparini G, Fox SB, et al. Quantification of angiogenesis in solid human tumorous; an international consensus on the methodology and criteria of evaluation. Eur J Cancer 1996; 32: 2474-2484.

28. Folkman J. Seminars in Medicine of the Beth Israel Hospital, Boston. Clinical applications of research on angiogenesis. N Engl J Med 1995; 333: 1757-1763.

29. Janowska-Wieczorek A, Majka M, Marquez-Curtis L, et al: $\mathrm{Bcr}$-abl-positive cells secrete angiogenic factors including matrix metalloproteinases and stimulate angiogenesis in vivo in Martigel implants. Leukemia 2002; 16: 1160-1166.

30. Gunsilius E, Duba HC, Petzer AL, et al. Evidence from a leukemia model for maintenance of vascular endothelium by bone-marrow-derived endothelial cells. Lancet 2000; 355: 1688-1691.

31. Green AR. Hemangioblast origin of chronic myeloid leukaemia? Lancet 2000; 355:1659-1660.

32. Buchdunger E, O'Reilly T, Wood J. Pharmacology of imatinib (STI571). Eur J Cancer 2002; 38 (suppl 5): S28-S36.

33. Michalak SS, Gil L. Patient with chronic myeloid leukemia challenge for primary care physician. Fam Med Prim Care Rev 2015; 17: 43-47.

34. Legros L, Bourcier C, Jacquel A, et al. Imatinib mesylate (STI571) decreases the vascular endothelial growth factor plasma concentration in patients with chronic myeloid leukemia. Blood 2004; 104: 495-501.

35. Holtz MS, Slovak ML, Zhang F, et al. Imatinib mesylate (STI571) inhibits growth of primitive malignant progenitors in chronic myelogenous leukemia through reversal of abnormally increased proliferation. Blood 2002; 99: 3792-3800.

36. Beham-Schmid C, Apfelbeck U, Sill H, et al. Treatment of chronic myelogenous leukemia with the tyrosine kinase inhibitor STI571 results in marked regression of bone marrow fibrosis. Blood 2002; 99: 381-383.

37. Simsek ET, Eskazan AE, Cengiz M, et al. Imatinib reduces bone marrow fibrosis and overwhelms the adverse prognostic impact of reticulin formation in patients with chronic myeloid leukemia. J Clin Pathol 2016; 69: 810-816.

38. Eliacik E, Isik A, Aydin C, et al. Bone marrow fibrosis may be an effective independent predictor of the TKI drug response level in chronic myeloid leukemia. Hematology 2015; 20: 392-396.

39. Dolgikh TY, Dominikova NP, Tornuev YV, et al. Incidence of myelofibrosis in chronic myeloid leukemia, multiple myeloma and chronic lymphoid leukemia during various phases of diseases. Bull Exp Biol Med 2017; 162: 483-487.

40. Thiele J, Kvasnicka HM, Schmitt-Graeff A, et al. Effects of the tyrosine kinase inhibitor Imatinib mesylate (STI571) on bone marrow features in patients with chronic myelogenous leukemia. Histol Histopathol 2004; 19: 1277-1288.

41. Rumpel M, Friedrich T, Deininger MW. Imatinib normalizes bone marrow vascularity in patients with chronic myeloid leukemia in first chronic phase. Blood 2003; 101: 4641-4643.

42. Ćojbašić I, Mačukanović-Golubović L, Mihailović D, et al. Improved prediction of clinical outcome in chronic myeloid leukemia. Int J Hematol 2015; 101: 173-183.

\section{Address for correspondence}

Irena Ćojbašić, MD, $\mathrm{PhD}$

Clinic of Haematology and Clinical Immunology

Clinical Centre Niš

48 dr Zorana Djindjica Blvd.

18000 Nis, Serbia

e-mail: icojbasic@gmail.com 